\title{
RESOLVING CONFLICT AND BUSINESS ANTHROPOLOGY
}

\author{
AlF H. WALle \\ UNIVERSITY OF ALASKA AT FAIRBANKS
}

\begin{abstract}
Disagreements and conflicts are natural, not abnormal. Various methods of dealing with such struggles exist. Although the standard tools of negotiation and decision making are useful, alternative techniques (such as mediation, arbitration, and litigation) are sometimes needed. In addition, processes of indigenous conflict resolution (that embrace local traditions) have a potential role, especially within small-scale, rural, and/or ethnically distinct communities. Business anthropologists have unique skills for facilitating conflict resolution in many situations.
\end{abstract}

Keywords: conflict resolution, indigenous people, business anthropology

\section{Accepting and Recognizing Conflict}

Conflict and disagreement are natural, not abnormal, and inevitably arise when different stakeholders experience and/or are impacted upon by divergent goals, beliefs, vulnerabilities, circumstances, and so forth. If not dealt with effectively, conflict (and issues related to it) can trigger tensions that undercut or inhibit positive working relationships between individuals and/or groups. To minimize and control these hurtful potentials, conflict often needs to be anticipated, managed, and mitigated.

Conflict can arise when goals are uncertain and/or when they are changing. Such responses are likely to emerge as a natural response to ambiguity. This is often the case when small and vulnerable communities experience significant and prolonged contact with outside intruders who offer disruptive, but seductive and possibly helpful, opportunities. Business anthropologists possess skills that can prove useful when addressing such situations.

When new and unprecedented conditions trigger conflict, for example, two factions (one "conservative", the other more "progressive" or "modern") 
are likely to arise. Each bloc might embrace distinctive and mutually exclusive thoughts regarding how to deal with the situations before them. Those with a more traditional orientation typically prefer the older style of life, cling to their heritage, and hesitate to accept changes that are triggered by outside contact. More "progressive" members of the community, in contrast, often welcome a greater embrace or alliance with the outside world and are more likely to be attracted by the options that it offers. The resulting tensions between these factions can undercut the internal harmony of a community as well as complicating and/or disrupting its negotiations with the outside world or potential collaborators. Hurtful and counterproductive tensions, rivalries, and responses often result.

In the heat of contention, mutual misunderstanding can easily emerge. Communications may break down or be misinterpreted. Emotions might interfere with, or prevent, even-handed communications between rivals. Such potentials exist internally in situations involving fellow members of the community as well as when dealing with outsiders.

Different levels of conflict, of course, may also exist; in one wellknown and intuitive model, some conflicts are minor and inevitable disagreements and pose little threat to cooperation and collaboration. Others are potentially disruptive and can destroy working relationships. These different levels of tension can be viewed with reference to an intuitive and commonly mentioned typology that ranges from minor disagreements, to chronic problems, to crises.

Whenever people are in contact, an array of trivial and commonly occurring difficulties inevitably arises. An adage from the military observes that "A griping soldier is a happy soldier". On the one hand, this saying underscores that people are always experiencing some sort of tension. On the other hand, when people are willing to acknowledge their disagreements (instead of hiding or internalizing them), relationships tend to be good, or at least workable.

If, on the other hand, an assortment of recurring trivial annoyances are ignored or left unresolved their disruptive potential can grow. Under these conditions, chronic patterns of disagreement may arise that, over time, take on a life of their own with disruptive consequences. Although no one particular incident might be significant, ongoing tensions can fester, take a toll, and trigger distrust in ways that cause alienation, disunity, and so forth. Frustrations and the anger it spawns can cause one or both parties to begin to question the value of the relationship. The insights and analytic tools of business anthropology can serve well when resolving such situations.

More significant are full-blown crises in which conflict and disunity potentially disable the relationships between parties. The resulting responses 
can be hurtful and costly to all. If such a trend continues, significant damage might occur. On some occasions, relationships cannot be mended. If less serious problems are addressed in a timely and equitable manner, however, disruptive tensions can often be minimized or mitigated. The insights of business anthropologists can provide invaluable insights when such tensions arise.

In tabular form, we find:

Table 1: A Continuum of Conflict

\begin{tabular}{|l|l|}
\hline LEVEL & ANALYSIS \\
\hline Common & $\begin{array}{l}\text { Some level of conflict or disagreement tends to be } \\
\text { inevitable. Such commonly occurring differences are not } \\
\text { significant problems. }\end{array}$ \\
\hline Chronic & $\begin{array}{l}\text { Minor problems repeatedly arise and/or minor conflicts } \\
\text { habitually crop up in ways that are unhealthy for } \\
\text { relationships. This situation can trigger more substantial } \\
\text { tensions. }\end{array}$ \\
\hline Crisis & $\begin{array}{l}\text { Disagreements grow to a level that threatens the } \\
\text { relationship. Forceful action tends to be needed to } \\
\text { counter such feelings and responses. On some occasions, } \\
\text { damage cannot be reversed. }\end{array}$ \\
\hline $\begin{array}{l}\text { DISCUSSION } \\
\text { destructive. Lower levels of conflict include minor problems that create } \\
\text { minimal threats to relationships. Should conflict become chronic, } \\
\text { however, a recurring and hurtful potential can arise. When crises emerge, } \\
\text { relationships are potentially undercut, requiring formal, forceful, and/or } \\
\text { systematic attention. The insights of business anthropology can be useful } \\
\text { in reducing and mitigating unhealthy tensions. }\end{array}$ \\
\hline
\end{tabular}

Thus, conflict is normal. It should not be viewed as an atypical twisting of relationships that are ordinarily completely harmonious. People have their own goals and attitudes. This reality needs to be accepted. By recognizing that conflict is to be expected, dealing with it in a sensible and 
effective manner becomes an easier task. The goal should be to accept conflict where it exists, work through it in positive and constructive ways, and minimize its hurtful potentials. Business anthropologists can serve as useful facilitators who advise and facilitate both outsiders and insiders.

\section{Conventional Methods}

A variety of strategies exist for dealing with conflict. One classic representation of an array of options is presented by Kenneth Thomas (1976) in his Handbook of Industrial and Organizational Psychology. Thomas discusses five basic strategies including "collaborating", "competing", "compromising", "accommodating", and "avoiding".

Collaborating can be characterized as "I win, you win". Different stakeholders work together to achieve objectives that, typically, are in their mutual interest. Although some disagreements may exist, these differences are addressed and mitigated; in the process, potentially hurtful impacts are reduced or mitigated.

Competition exists where an "I win, you lose" attitude prevails. It is characterized by a potential for the person, group, or organization to lose or gain, coupled with the need to look after self-interests. The focus is upon winning and losing, not parity and equity. Many mainstream negotiations are based upon competition and the results are judged by a standard suggested by the competitive model. Many small-scale societies, in contrast to this orientation, focus upon the community (not strategic orientations for dealing with the outside world). Where this situation occurs, competitive methods that are popular in the mainstream world might not fit well within many indigenous, ethnic, and rural communities. Business anthropologists can serve by providing an insightful understanding of the key orientations of the culture. By doing so, the effectiveness of an "I win, you lose" strategy can be calculated and alternative strategies can be better envisioned.

In situations where a "You give, I give" attitude prevails, the spirit of compromise prevails. Doing so involves all involved parties giving up something of value, while each simultaneously gains at the other's expense. The common good (or at least the feelings and attitudes of the involved stakeholders) is considered and addressed. Under such circumstances, some issues might be left unresolved, because when people give in to the wishes or demands of others they are not totally happy with the results. Because these (often sensitive) areas of divergence are left unreconciled, reaching a workable compromise can often proceed more quickly than if all issues had to be totally resolved before any agreement 
could be reached. Although compromise can be a good tactic, negotiators need to be careful not to give up too much. When dealing with diverse groups that might not understand each other, an objective social scientific appraisal may be an invaluable tool. Business anthropologists can serve in this regard.

In accommodating, one party allows the other to win. This process can be described by the phrase "I lose, you win". On some occasions, a concession or accommodation might not impact upon one party very much, even though it has great value to the other. Under these circumstances, accommodating can be a good strategy that makes others happy although the cost is minimal. Doing so can help maintain harmony and build goodwill. In other situations, one party might be wrong and, as a result, providing an appropriate accommodation is the proper course of action. Some battles, furthermore, just can't be won, so giving up without a fight can be an effective response. When negotiators are making concessions, they often need to conduct some sort of cost-benefit analysis. A cultural analysis of all impacted stakeholders provides valuable information that is vital to the decision-making process. Business anthropologists are especially qualified to do so.

In avoiding, there are "No winners and no losers". Under such circumstances, key and important issues might be left unaddressed in order to reduce strife in the short term. This tactic can make it easier to concentrate upon other issues that appear to be more important and/or resolvable. Although temporary harmony or ad hoc cooperation might prevail, the causes of tension can be left unresolved. On some occasions, putting off dealing with conflict might merely postpone future tensions; doing so can outweigh the immediate benefits.

Thus, a wide range of strategies and tactics exist when responding to conflict. Presented in tabular form, we find:

Table 2: Styles of Conflict Response

\begin{tabular}{|l|l|}
\hline STYLE & ANALYSIS \\
\hline Collaborating & $\begin{array}{l}\text { I win, you win: Mutual goals are addressed. Work } \\
\text { though differences. Find creative solutions. Satisfy } \\
\text { both parties. }\end{array}$ \\
\hline
\end{tabular}




\begin{tabular}{|l|l|}
\hline Competing & $\begin{array}{l}\text { I win, you lose: The issues addressed are very } \\
\text { important. A decision is needed immediately. Can't } \\
\text { be a tie. Parties must stand up for themselves. } \\
\text { Personal and very competitive. }\end{array}$ \\
\hline Compromising & $\begin{array}{l}\text { You give, I give: All stakeholders give up } \\
\text { something. Common good facilitated. Some } \\
\text { differences might be unresolved. Easier and quicker } \\
\text { than other methods. But your position can be } \\
\text { "picked away". }\end{array}$ \\
\hline Accommodating & $\begin{array}{l}\text { I lose, you win: you don't really care. You are } \\
\text { wrong. You can't win. Maintaining harmony is } \\
\text { important. }\end{array}$ \\
\hline Avoiding & $\begin{array}{l}\text { No winners, no losers: Key issue left unaddressed or } \\
\text { sidestepped, but postponing might make matters } \\
\text { worse. If avoidance is employed, the ultimate } \\
\text { resolution might not have your input. }\end{array}$ \\
\hline $\begin{array}{l}\text { DiSCUSSION } \\
\text { dealing with conflict exist. Cultural circumstances often influence what } \\
\text { approach is most effective in a particular situation. Social scientists, such } \\
\text { as business anthropologists, have a significant role in analyzing how } \\
\text { different styles of resolution are likely to function in specific contexts. }\end{array}$ \\
\hline
\end{tabular}

Thus, a variety of methods for dealing with conflict exist. Understanding them can provide vital tactics for negotiating with others. People from specific cultural groups tend to respond in a certain, predictable manner; as a result their style of dealing with conflict can be viewed as a "default setting". A range of other default settings often exist; that is the next topic of discussion.

\section{"Default Settings"}

In addition to the fact that various methods of dealing with conflict exist, individual people and specific groups tend to think and act in a 
predictable, systematic, and "pre-programmed" manner. Computers, by analogy, tend to be "preloaded" with a variety of predetermined "default settings" that are not inherent or universal. The same is true when dealing with diverse people: to a large extent different peoples are "programmed" by their cultures, traditions, and heritage. The social sciences, such as anthropology, provide tools for identifying these patterns of response. As a result, business anthropologists have a role to play when people from different backgrounds seek to negotiate and resolve conflicts.

Representative default settings exhibited by people are influenced by variables such as (1) the culture, (2) values, and (3) paradigms. Each is briefly discussed below. Other influences (such as needs) clearly exist, but are not discussed here because they are considered elsewhere. The discussions presented here, therefore, should be viewed as representative, not exhaustive.

Culture: Viewed broadly, culture refers to the collective, learned knowledge that the human race, as a species, has acquired, preserved, and transmitted. Viewed more narrowly, culture refers to one specific way of being human. Different cultures possess their own distinctive rules, priorities, codes of behaviour, and so forth. Thus, talking about "Japanese" and "American" cultures can be meaningful and appropriate. Terms such as "national character" are sometimes used to identify such phenomena. Acknowledging that these distinctions exist does not imply that all people totally embrace the culture of which they are a part, but merely that certain distinctive and recognizable patterns exist. In my Rethinking Business Anthropology (2013), such issues are discussed at greater length with reference to business strategy.

Cultures tend to provide their members with a wide array of default settings that encourage specific ways of responding and interpreting the actions of others. The resulting tendencies and reactions can become so ingrained that social actors are likely to assume that the type of responses they make are universal, inherent, and innate, and exhibited by all people. Misreading others in such a manner can trigger potential clashes, or at least create an atmosphere of confusion and misunderstanding. Business anthropologists can help provide more appropriate visions of others, how they think, and why they act the way they do.

Values: Values are standards regarding what are important, acceptable, revered, easily dismissed, and so on. People's cultural backgrounds have a significant role in determining what values they embrace or reject, and why they do so. In addition, values can be influenced by other issues that transcend the generic culture (such as age and sex). 
Baby boomers in the United States, as is widely known, have tended to be distinctive ever since they established their "youth culture" in the 1960s. As a significant faction of the population, baby boomers continue to be distinctive. Their patterns of response can be explained (1) with reference to the specific needs of this segment at particular times and (2) with reference to the fact that a large cohort of individuals from this age group shares a number of key values. In many cultures, being a member of a particular "age grade" is even more important than in North America because relationships are more formally structured or institutionalized with reference to age groupings.

For whatever reason, specific clusters of stakeholders might possess values that are internally homogeneous, but distinctive from the broader culture or society. In the early $1990 \mathrm{~s}$, I met a colleague from the University of Leipzig at a professional conference. Greeting her, I said "I see you are from East Germany," but quickly corrected myself to "Germany", in order to acknowledge the recent reunification of the country. She responded in a cold and deliberate manner, "You were right the first time, I am from East Germany."

Thus, while many Germans were celebrating the reunification of their nation, some people of a certain age and from a certain region were not happy with the new state of affairs. Their default settings, most likely, were based, at least in part, upon the values held by those who were opposed to the new political realities.

Like those East Germans who were dismayed by reunification, many indigenous, ethnic, and rural communities are also subjected to traumatic, albeit exciting and transformational, changes. Not all people respond to these emerging situations in the same way because specific segments possess distinctive values. Business anthropologists have a potential role in recognizing and articulating these important differences.

Paradigms: People tend to embrace over-arching systems of belief that colour the way in which they view the world. Even when these patterns are obviously "wrong", they can possess profound staying power and continue to wield a powerful influence. The plight of Galileo and his attempts to convince people that the earth moved around the sun is a case in point. The old belief that the sun moves around the earth was so strong that, in the short term, it could not be successfully challenged.

Another set of paradigms that have proved to be irreconcilable in some circles (at least in the United States), is the dyad of "biological evolution" vs. "intelligent design". The concept of evolution, of course, assumes that the species alive today are products of what is usually envisioned as the "survival of the fittest" or, more accurately, today's living things are 
offspring of ancestors who were able to reproduce and pass their genes to future generations. Over many generations, the resulting patterns of selective reproduction lead to evolution and change.

Intelligent design, in contrast, is the theory that a force beyond random events is at work (typically envisioned as an all-powerful, rational God who is actively involved in the world. This force is believed to have designed and created life).

In the United States, both of these views are currently held by significant segments of the population. Although, over time, trends may shift, these beliefs are currently unshakeable among loyal adherents to both positions.

Neoclassical economics is another paradigm that provides an overarching interpretation of human response that asserts that economic behaviour is rational and universal. The neoclassical paradigm can be challenged by both behavioural economics and the substantive economic model.

Paradigms (patterned ways of thinking that are often relied upon in a "knee jerk reaction" manner) are thus powerful, ingrained, and often immune to change.

In general, default settings are not universal and inevitable. They are patterned variations that mould people to think and act in a certain way. Recognizing these default settings can be an important means of understanding how people think and react.

In tabular form, we find:

Table 3: Default Settings

\begin{tabular}{|l|l|}
\hline SETTING & ANALYSIS \\
\hline Culture & $\begin{array}{l}\text { From a micro perspective, "culture" refers to a } \\
\text { particular way of life as practiced by a specific people. } \\
\text { The culture is learned, handed down, and typically } \\
\text { embraced by people, although variation often exists } \\
\text { among its member. Even when change inevitably takes } \\
\text { place over time, recurring and predictable patterns make }\end{array}$ \\
$\begin{array}{l}\text { it possible to refer to "American, "Japanese", } \\
\text { "Iroquois", "Maori", etc. cultures. }\end{array}$ \\
\hline
\end{tabular}




\begin{tabular}{|l|l|}
\hline Values & $\begin{array}{l}\text { Values involve what people believe is important, moral, } \\
\text { significant, and so forth. Values can be based upon } \\
\text { general cultural criteria as well as more circumscribed } \\
\text { influences, such as age and sex. }\end{array}$ \\
\hline Paradigms & $\begin{array}{l}\text { Paradigms are general theories or perspectives that are } \\
\text { embraced and form a systematic and relatively rigid } \\
\text { way of processing information. }\end{array}$ \\
\hline Others & $\begin{array}{l}\text { This listing is meant to be illustrative, not exhaustive. A } \\
\text { wide variety of default settings exists. When } \\
\text { considering a situation, look for whatever important } \\
\text { covert influences exist. }\end{array}$ \\
\hline $\begin{array}{l}\text { DISCUSSION } \\
\text { "Default settings" are largely covert influences upon thought and action. } \\
\text { Social scientists, such as business anthropologists, are well-suited for } \\
\text { analyzing these patterns of response and providing a better understanding } \\
\text { of how people think and act. }\end{array}$ \\
\hline
\end{tabular}

Default settings potentially limit objective and thoughtful discussions between people as well as covertly influencing their relationships. The fact that different people(s) possess distinctive default settings can create situations where those holding contradictory views and orientations may have trouble understanding and/or responding to each other. This possibility can exert hurtful consequences. By being aware of such default settings, however, finding ways to acknowledge and mitigate differences between people might become easier.

This observation (and other thoughts provided above) set the stage for a discussion of conflict as well as ways to envision and respond to it.

\section{Beyond Conventional Negotiation}

Although a wide variety of methods for forging agreements exist, they are not always effective. Some disagreements are so great that the involved parties cannot easily form a working relationship even when doing so is in their mutual interest.

Within the mainstream world, three systems have arisen that expand beyond the usual processes of negotiation. They include meditation, 
arbitration, and litigation. After these commonly employed options have been reviewed, a separate section is devoted to alternatives (collectively referred to as "indigenous conflict resolution") that arise from the cultural traditions of the people involved. The potential role of business anthropology when such methods are being employed is emphasized.

Mediation (Boulle 2009) is a system of resolving conflicts by employing the services of a mutually trusted third party(s) who helps others to resolve problems or disagreements. Not serving as counsellors or advisers for only one partisan group, the facilitator(s) maintains a neutral stance, striving to help all involved parties to better understand the situation and the options that are available to resolve it. In some circumstances, a mediator has expert knowledge regarding the specific issue under dispute. Under these circumstances, mediators are sometimes referred to as conciliators.

The proceedings that result from mediation or conciliation are typically not binding (as is the case in arbitration and litigation) unless the parties decide to forge a formal settlement when the mediation proceedings are successful. The matters under discussion, furthermore, tend to remain private (as opposed to legal proceedings where the facts and actions become part of the public record.) In many places, mediation has emerged as a profession that typically requires formal training and certification.

Although parties enter into mediation with the hope and expectation of finding a workable solution, resolving the issue is not compulsory or mandated. Participants, therefore, may unilaterally walk away from the proceedings at any point and for any reason. The simple fact that the parties are willing to seek mediation, however, tends to indicate that they want a resolution, and that a good chance of success exists.

In many pre-industrial, rural, and small scale societies, local leaders, elders, or other respected individuals have long functioned in a role that closely parallels mediators. When this is true, such communities are likely to feel comfortable with this method of conflict resolution. Where this is true, local people may be willing to accept mediation instead of relying upon systems (such as arbitration or litigation) that are more formal and potentially alienating.

Styles of mediation can be developed that account for the distinctiveness of the participants. A method of mediation within education, known as "peer mediation", for example, employs fellow students as mediators. Being similar to the disputants, these peers are potentially better able to understand the situation and broker a solution. The same "peer approach" can potentially be adopted when people from distinct cultural backgrounds seek to resolve a conflict or dispute. 
Mediation is a "non-adversarial" method of resolving disputes in which the goal is not to assign blame and responsibility, but to forge solutions. Indigenous systems of conflict resolution often follow this approach. Thus, Native American court systems tend to focus upon mitigating problems and reducing pain instead of being preoccupied with who is "right" or "wrong" (from personal knowledge from working with Alaska Native courts).

A key technique used by many Native American peoples is the "talking circle" in which all interested participants are given the floor and allowed to speak without interference in a manner that often leads to nonargumentative brainstorming regarding how to resolve the conflict. As the talking circle example suggests, indigenous, ethnic, and rural peoples might be comfortable with a mediation-style of conflict resolution because they tend to practice methods that are analogous to it.

An emerging and innovative approach to mediation that has evolved in the developed West is "party-directed mediation" (Billiokopf 2014), which involves the facilitator(s) dealing with each party separately in "precaucus" meetings in order to improve their abilities to effectively present their points of view. This preliminary coaching allows all the stakeholders to more effectively articulate their concerns and demands. This type of preparation can be of value to participants who need to be groomed and coached; many indigenous, ethnic, and rural people fall into this category because they are not experienced with dealing with the mainstream world and its methods in formal ways.

Transformative mediation (Bush and Pope 2002) looks at conflict as a crisis in communication. The goal of this specialized approach is to improve the abilities of the parties to communicate, understand the issues, and reduce negative and hostile feelings, while gaining the ability to interact in productive ways. Because cultural differences can lead to misunderstanding, this focus is of potential value. Business anthropology can be useful in this regard.

Thus, mediation provides a range of practical techniques for resolving conflicts that are widely used in the Western and developed regions. It is voluntary and not legally binding, but it often leads to a fruitful resolution of differences. Although not a product of the indigenous, ethnic, or rural communities, mediation shares important characteristics of conflict resolution methods that are practiced by many such peoples.

In tabular form, mediation can be depicted as: 
Table 4: Mediation

\begin{tabular}{|l|l|}
\hline ISSUE & ANALYSIS \\
\hline Characteristics & $\begin{array}{l}\text { Mediation is voluntary, not binding. Parties are } \\
\text { involved because they choose to participate. Not } \\
\text { participating or withdrawing from mitigation are } \\
\text { options. The action is private and details are not } \\
\text { disclosed to the public. }\end{array}$ \\
\hline Benefits & $\begin{array}{l}\text { Parties have greater control over how the issues } \\
\text { will be discussed and they are not obligated to } \\
\text { accept a solution unless they choose to do so. Many } \\
\text { indigenous, ethnic, and rural peoples might already } \\
\text { practice methods that are analogous to mediation } \\
\text { and feel comfortable with the process. A specific } \\
\text { proceeding might be conducted in a culturally } \\
\text { sensitive manner. }\end{array}$ \\
\hline $\begin{array}{l}\text { Drawbacks } \\
\text { MISCUSSION } \\
\text { is collow the suggestions } \\
\text { alienating participants. Business anthropologists have a valuable } \\
\text { contribution to make because of their cultural and societal insights. }\end{array}$ \\
\hline $\begin{array}{l}\text { There is no guarantee that the issue will be } \\
\text { resolved. Parties cannot be forced to participate. }\end{array}$ \\
\hline
\end{tabular}

Mediation, therefore, is a voluntary system that many indigenous, ethnic, and rural people can be comfortable with. The risks of involvement are low because no mandated actions will result from being involved with the process. When cultural differences are great, and different stakeholders might not understand each other, business anthropologists are uniquely positioned to serve as advisers or facilitators under such circumstances.

Arbitration: In arbitration (Steven and Sherffrin 2003), the participants allow a neutral third party to pass judgment regarding the matter under discussion with the resulting decision becoming legally binding and enforceable by the courts. The term "non-binding arbitration" 
is sometimes heard, but is not employed in this discussion (where the term "mediation" is reserved for non-binding forms of alternative conflict resolution). "Arbitration" is used when referring to situations where definitive and obligatory rulings are made that cannot be rejected (except under extraordinary circumstances).

Arbitration is often used as a substitute for court actions, although (as with mediation) the findings are not public. A facilitator (or in some cases a panel) renders judgment. The format, process, and "feel" of the proceedings often resemble a trial, although typically streamlined and quicker. Nonetheless, rules of evidence, and so forth, apply. The arbitrating official (or panel) makes a decision that the parties are not able to reject. The judgments tend to be final.

In some cases, a contract or prior arrangement might stipulate that disagreements will be resolved via arbitration. Where such a requirement does not exist, parties are free to reject an offer to arbitrate. Once the parties choose to participate in arbitration, however, decisions are final, enforceable, and they cannot be denied or ignored.

Those who consider entering into a contract that stipulates that future disagreements will be settled via arbitration might need to be very careful in order to ensure that the arbitrators who make decisions are culturally competent. Because business anthropologists have expertise both in business and cultural affairs, they possess invaluable skills of potential value in facilitating equitable arbitration proceedings.

One advantage of arbitration is that the parties often have a degree of control over who will pass judgment. In court proceedings, in contrast, the parties probably have little or no say in who will preside as judge and they have only limited control over the makeup of the jury. This situation might put indigenous, ethnic, and rural people at a disadvantage because the decision makers might not be adequately familiar with the cultural and situational context of the case. If arbitration is chosen, in contrast, those involved are likely to have a greater say in choosing who will render judgment. As a result, business anthropologists might serve as consultants who help clients choose appropriate arbitrators and/or serve as advisers or consultants who provide cultural insights to those deciding the case.

As with mediation, arbitration is relatively speedy, cheap, and the findings are confidential. Presented in tabular form, we find: 
Table 5: Arbitration

\begin{tabular}{|l|l|}
\hline ISSUE & ANALYSIS \\
\hline Characteristics & $\begin{array}{l}\text { Binding. Formal. Court-like. Findings are private } \\
\text { and are not made known to the public. }\end{array}$ \\
\hline Benefits & $\begin{array}{l}\text { Quick and cheap. The ability to choose arbitrators } \\
\text { that are culturally sensitive potentially exists in } \\
\text { some cases. }\end{array}$ \\
\hline $\begin{array}{l}\text { Drawbacks } \\
\text { Some participants might not feel comfortable with } \\
\text { the Western, court-like format. Care may need to be } \\
\text { taken to insure the arbitrator(s) is culturally } \\
\text { competent. Appealing or overturning a decision is } \\
\text { difficult. }\end{array}$ \\
$\begin{array}{l}\text { DISCUSSION } \\
\text { Although arbitration outwardly resembles court action, it is distinct from } \\
\text { it. It is a streamlined method of resolving differences that is not public. } \\
\text { Arbitration is often preferred because it is cheap and quick. Some } \\
\text { contracts specify that disputes will be resolved via arbitration. Indigenous, } \\
\text { ethnic, and rural people may need to be careful to ensure that if arbitration } \\
\text { takes place, it will be conducted in a culturally competent manner. } \\
\text { Business anthropologists can help insure this potential. }\end{array}$ \\
\hline
\end{tabular}

Arbitration can be viewed as a middle ground between non-binding mediation and the court system. It operates outside the legal framework but does so in a manner that is reminiscent of legal proceedings. The system often provides a means of ensuring that culturally sensitive individuals will decide the case. It is relatively cheap and quick. Business anthropologists are well positioned to serve in this regard.

Litigation: In everyday language, litigation is said to take place when someone is sued in court. These actions are civil, not criminal in nature. In litigation, a "plaintiff" claims to have been damaged or hurt by the actions of a "defendant". As a result, some sort of remedy or compensation is demanded from the defendant.

If the plaintiff is successful, the court will require the defendant to do something that might range from providing compensation, to adhering to 
an injunction that requires the defendant to do (or not to do) something. A "declarative judgment" (Bray 2010), for example sets the record straight in order to prevent further disagreements.

Although people and organizations are typically sued, it is often possible for an individual or group to sue a government or public entity. The Maya of Belize, for example, have recently sued their government and won.

In general, a lawsuit begins when the court receives a complaint that asserts that the plaintiff(s) has been injured by the defendant for reasons that are detailed. Selecting the particular court that will hear the case is often a key strategic move. This is known as "choosing the proper venue". In Alaska (USA), for example, Native, State, and Federal courts might all have potential jurisdiction if Alaskan Natives are involved. Once a case has been started, furthermore, there is a tendency for the other courts to honour the jurisdiction of that court and not get involved. Because of this common practice, future litigants often initiate a lawsuit in the venue that is most beneficial to them. This tactic is known as "racing to the courthouse".

After the initial paperwork has been completed, the plaintiff is given a "summons" and a copy of the complaint that is officially and ceremoniously delivered to the defendant. This document notifies the defendants regarding the nature of the lawsuit and states details, such as when the individual must appear in court, and so forth.

The actual trial, of course, is a complicated matter that is typically the realm of professionally trained lawyers. No advice will be given here because a little knowledge is a dangerous thing. In general, the burden is upon the plaintiff to prove that damage was done by the defendant and the job of the defence team is to derail that effort. All sorts of complicated procedures exist that lawyers strategically use to accomplish their respective goals. Eventually a judge or a jury renders the verdict. After that, a lengthy and complicated appeals process potentially begins.

All of this is typically costly and time-consuming. Lacking adequate funding, many potential plaintiffs are unable to take legal action. Large firms, for example, possess the resources needed to document wrongdoing and to sue individuals who violate copyright or intellectual property rights. Members of small indigenous, ethnic, and rural enclaves, in contrast, are often not able to gather evidence and fund a court action even when they have a valid claim. As a result, these small and weak entities are denied the protection that is readily available to large and rich organizations. Business anthropologists can serve as advisers and/or help to level the playing field. 
Those rendering judgments, furthermore, may not be familiar with the situations faced by indigenous, ethnic, and rural peoples. When those responsible for rendering verdicts lack adequate knowledge of the situation or the people involved, potential inequity can result that needs to be forcefully addressed and mitigated. Those considering lawsuits are urged to be aware of this potential problem and, where necessary, devise ways to diminish it. Business anthropologists have a role in this regard.

Under some circumstances, furthermore, a court case may be precedent-setting and/or be used to clarify a law. Where such a situation exists, the decision rendered in one litigation may help many other people to gain equitable treatment - this benefit does not occur when mediation and arbitration are used to resolve conflicts, because these proceedings are outside of the law. In tabular form, litigation can be described as:

Table 6: Litigation

\begin{tabular}{|l|l|}
\hline ISSUE & ANALYSIS \\
\hline Characteristics & $\begin{array}{l}\text { Legal, formal, costly, time-consuming, Appeal } \\
\text { possible. }\end{array}$ \\
\hline Benefits & $\begin{array}{l}\text { Becomes part of the public record. If the "race to } \\
\text { the courthouse" is successful, a good venue may be } \\
\text { available. Decision can set a precedent. }\end{array}$ \\
\hline Drawbacks & $\begin{array}{l}\text { Costly. Time-consuming. Appeals may stretch out } \\
\text { over a long period. Relatively little control over } \\
\text { who will decide the case. }\end{array}$ \\
\hline $\begin{array}{l}\text { DISCUSSION } \\
\text { Litigation (suing) is complicated, costly, time-consuming, and risky. Court } \\
\text { cases, however, may resolve issues in ways that set precedents that help } \\
\text { other people in similar situations. Business anthropologists have a } \\
\text { potential role in helping people deal with litigation in an effective and } \\
\text { culturally appropriate manner. }\end{array}$ \\
\hline
\end{tabular}

A variety of methods of conflict-resolution thus exist in the mainstream world. "Alternative methods" include mediation and arbitration. Legal remedies and the court system are always available. A problem, however, 
may be that these options tend to be products of the mainstream culture and, therefore, they are potentially insensitive to the needs and perspective of indigenous, ethnic, and rural peoples. Because of their cultural knowledge, business anthropologists have an important role in helping these people function effectively when resolving conflicts.

\section{Indigenous Conflict Resolution}

Local people often benefit by embracing the techniques of negotiation and conflict-resolution that have been developed by outsiders. An alternative exists in which the proceedings of a conflict-resolution activity adhere to peoples' traditional methods of social control and negotiation. This strategy has a long history and it has been effective in diverse places.

After the "fall of the Roman Empire" in $476 \mathrm{AD}$, for example, the Latin people were allowed to continue using Roman law among themselves (although special rules applied when others were involved). Odoacer, whose regime replaced the Empire, obviously understood that a people are subtly and intimately connected to their legal tradition, and he allowed it to continue functioning.

Jumping forward to the modern colonial era, the British Empire's policies of controlling and administering its territories typically involved maintaining the existing regimes and methods of control as long as loyalty to England existed. Local and indigenous codes of law and conflict resolution were largely preserved thanks to this administrative strategy.

In the United States, indigenous peoples are viewed as dependent, internal nations that retain the right to maintain their own systems of law and social control. All of these examples demonstrate that a long tradition of validating and nurturing local social control goes back to ancient times and survives to this day.

Depending upon the region or country where a dispute takes place, indigenous courts may or may not exist. Where they do function, however, certain limitations have probably been imposed by the sovereign government. In the United States, for example, the "Major Crimes Act" gives Native courts only limited authority in criminal cases, although in civil matters jurisdiction has not been significantly undermined.

An alternative to unique traditions, however, asserts that a universal and culture-free system of law and conflict-resolution should replace the local heritage. The Age of Enlightenment that dominated eighteenthcentury thought provides a classic example of that policy. The justification for universal standards was based upon the belief that rational legal 
systems are superior to those that spring from tradition or emotion. These superior methods, the logic continues, should be unanimously applied.

A self-conscious experiment of policy and strategy that reflects the quest for rational codes of law to be universally applied is the Napoleonic Code. After coming to power, Napoleon commissioned a panel of respected jurists to create a legal framework that would be rational, consistent, objective, efficient, and fair to all. When Napoleon conquered a territory, the resulting Code was introduced as the new law of the land. Of all his achievements, Napoleon was most proud of this legal system, observing, "My true glory is not to have won 40 battles... what will live forever is my Civil Code." (Wanniski 1998:184).

Nonetheless, dissatisfaction arose. Complaints arose that laws are not merely rational, objective, and universal rules. Legal frameworks might also possess a specific cultural slant that conflicts with the people and their ways of life. Speaking about Catalonia, Enric Prat de la Riba (1998) observes that people "spoke of law as a live entity, which is spontaneously produced by national consciousness... They said that law and language were both manifestations of the same national spirit..." In this way, the vision of an impartial, culture-free, and universal law was challenged. As an alternative, Napoleon's universal code of law was depicted as a thwarting and alien artefact, not as a universal and liberating tool. According to this view local and cultural codes should be preserved.

Are mainstream methods of negotiation and conflict resolution following in the path of the Napoleonic Code? Apparently so, because they can easily be viewed as a generic system that strives for universal application while ignoring the full context within which decisions take place.

Alternatives to universal strategies include relying upon rules, codes of behaviour and methods of conflict resolution that already exist in regions and communities. When talking about mediation, for example, the point was made that it is often analogous to the mechanisms that already exist and function within local communities. As a result, this approach may be successful in these environments. Despite parallels, however, mainstream mediation is an intrusive, outside set of techniques that are imported. As a result, mediation might not adequately mesh with local peoples and the challenges they face.

A more culturally- and regionally-sensitive approach is to employ techniques that exist locally instead of relying upon outside methods that resemble them in some ways. Initiatives that strive to do so are collectively known as indigenous conflict resolution. A useful review of these techniques is provided by Carlo Osi in his "Understanding Indigenous 
Dispute Resolutions and Western Alternative Dispute Resolution” (2008), a monograph-length article appearing in the Journal of Conflict Resolution.

Indigenous conflict-resolution mechanisms employ local and traditional systems. Doing so can be an effective means of sidestepping potential tensions that could otherwise be caused by outside governmental, court, military, or police involvement, and/or interference. This tactic can provide significant benefits where political strife exists and/or where hostility to outside influences or pressures might arise.

This process (which tends to be tailored to particular regions, groups, and circumstances) often seeks to build a broad consensus through a process of open discussions. In many small-scale societies, for example, the opinions of respected elders typically exert significant influence. "Elders", of course, are not merely old people; they are revered role models who have won the respect of the community and, perhaps, serve as informal ambassadors for their cultures, societies, and traditional ways of life.

Disputants are often more willing to accept the opinions of esteemed local leaders than the advice of outsiders. Even though such home-grown advisers tend to have no formal "authority", they often wield great clout. When indigenous conflict resolution is successful (often with the involvement of such informal leaders), tensions may be resolved and unity built. Respected local leaders (elders and so forth) are often invaluable in this regard.

Caution may need to be taken under some circumstances because a wide range of initiatives (such as those involving the roles of women) might be at odds with local traditions. Such initiatives can fail if they attempt to accomplish too much too quickly. Today such issues are important points of contention and opinions are often heated. Great care needs to be exercised under such circumstances.

The United Nations Millennium Development Goals, for example, was designed to alleviate poverty in developing countries. Part of its agenda involves advocating for women's rights in areas including education and health issues (including birth control). Doing so has caused some regions, where tightly defined sexual roles exist, to reject these goals. Thus, if campaigns of indigenous conflict-resolution (such as those involving women's rights) are significantly more progressive than the communities where they are being introduced, resistance might develop. When attempting to address reformist agendas using indigenous dispute resolutions, risks and potential tradeoffs might need to be considered.

Furthermore, outside organizations (such as partnering companies), may hesitate to use these systems because of a lack of familiarity with 
them. These outsiders might be especially leery if the judgments are binding. Outside organizations, however, might be willing to participate in such discussions if they function as a form of mediation that is not binding. In many cases, adhering to local traditions (even in a non-binding manner) can build greater understanding and trust on both sides. In tabular form, we find:

Table 7: Indigenous Conflict Resolution

\begin{tabular}{|l|l|}
\hline ISSUE & ANALYSIS \\
\hline Characteristics & $\begin{array}{l}\text { Based on local traditions. Typically administered } \\
\text { locally. Cultural leaders, such as elders, may play a } \\
\text { significant role. }\end{array}$ \\
\hline Benefits & $\begin{array}{l}\text { Often more concerned with results, not determining } \\
\text { who is right or wrong. Culturally appropriate. } \\
\text { Greater chance the findings will be respected by } \\
\text { local people }\end{array}$ \\
\hline $\begin{array}{l}\text { Drawbacks } \\
\text { Not precedent-setting. Outsiders might not want to } \\
\text { be bound by findings. }\end{array}$ \\
$\begin{array}{l}\text { DISCUSSION } \\
\text { Although other methods, such as mediation, may resemble or be analogous } \\
\text { indigenous conflict resolution embraces the mechanisms and } \\
\text { traditions of a people. It deals with issues at a grassroots, local level and } \\
\text { often gains local consensus as a result. The insights of business } \\
\text { anthropology can be invaluable when dealing with such indigenous } \\
\text { methods. }\end{array}$ \\
\hline
\end{tabular}

Indigenous conflict resolution involves using local traditions to settle disagreements. It is often employed as a technique to help the people of a region to address their arguments in a familiar way that is understood and respected.

These methods can be of potential value when outsiders seek to address tensions, misunderstandings, and clashes with local communities. When doing so, the outsiders overtly show respect for the people they are dealing with. Although these outsiders will probably hesitate to use these 
grassroots forms of resolution in ways the result in binding obligations, these methods might be useful in building the rapport and understanding that can provide insights needed for constructive action.

\section{Conclusion and Discussion}

The usual techniques of negotiation are often unable to deal with all sensitive issues. Conflict is universal because people have different goals, needs, and vulnerabilities. Thus, disagreements between both individuals and groups are often inevitable. This is natural.

Poorly managed conflict can lead to hostility that undercuts cooperation. Well managed conflict, on the other hand, may foster understanding, mutual respect, and can lead to equitably resolving issues in a manner that leads to future harmony.

Mainstream methods of resolving conflicts include mediation arbitration, litigation that ranges from non-binding discussions to legal actions with verdicts that are enforceable by law. Although these mainstream methods are well-known, on some occasions, techniques based upon local traditions may not suffice or be preferable. When this is the case, a system of indigenous dispute resolution may be most appropriate.

When dealing with culturally distinct groups, business anthropologists possess a unique toolkit of potential value to all impacted stakeholders, including mainstream intruders and members of local populations. By focusing upon cultural distinctiveness, business anthropologists have a significant contribution to make when conflicts exist and when strategies of resolving them are developed.

\section{References}

Billikopf, Gregorio (2014) Party Directed Mediation: Facilitating Dialogue Between Individuals (University of California Press).

Boulle Laurence (2009) Mediaion: Principles processes, Practice (Australia: Butterswortrh. $2^{\text {nd }}$ edition.

Bray, Samuel (2010) "Preventative Adjudication" University of Chicago Law Review 77 1275)

Bush, R.A.B. and Pope, S. G. (2002) "Changing the Theoretic Underpinnings of Mediation: Implications for Practice and Policy" Pepperdine Dispute Resolution Law Journal (3) 1 39-65

Enric Prat de la Riba, La nacionalitat catalana, 4th ed. (Barcelona: Edicions 62, 1998), 46. Quoted from Jacobson, Stephen (2002) "Law 
and Nationalism in Nineteenth-Century Europe: The Case of Catalonia in Comparative Perspective" Law and History Review (summer.

Osi, Carlo (2008) "Understanding Indigenous Dispute Resolution Processes and Western Alternative Dispute Resolution" Journal of Conflict Resolution pp. 164-229.)

Sullivan, Authur, Sheffrin, Steven M (2003) Economics: Principles in Action (New Jersey: Pearson).

United Nations Development Goals Website.

Thomas, Kenneth, (1976) Handbook of Industrial \& Organizational Psychology (Chicago, Rand McNally).

Walle, Alf H. (2013) Rethinking Anthropology (Greenleaf)

Wanniski, Jude (1998). The Way the World Works. Regnery Gateway. 